\title{
The temporal (in)stability of the unemployment and crime relationship
}

\author{
Olivia K. Ha, PhD Candidate \\ oha@sfu.ca \\ School of Criminology, Simon Fraser University \\ Martin A. Andresen, PhD \\ m.andresen@griffith.edu.au \\ School of Criminology and Criminal Justice, Gold Coast Campus, Griffith University \\ Parklands Dr, Southport QLD 4215, Australia \\ Garth Davies, PhD \\ garthd@sfu.ca \\ School of Criminology, Simon Fraser University
}

\begin{abstract}
The complex relationship between crime and economic change has had a long pedigree in criminological research. This paper considers the temporal stability of the Cantor and Land (1985) model of unemployment and crime using a decomposition model of Canadian provinces, 1981-2009. We include multiple economic measures for a more comprehensive representation of economic performance, allowing for the estimates of long- and short-run unemployment effects to vary over time. We undertake this analysis considering 12 crime types, finding strong support for the Cantor and Land (1985) model in both property and violent crimes. However, in a number of cases we find that there is significant variation of these relationships over time. This result implies that support for this model depends on the time period analyzed and that any policy derived from this model of unemployment and crime is time-period dependent.
\end{abstract}

Keywords: Unemployment; crime; panel data; temporal stability; decomposition model

Running head: Temporal stability of unemployment and crime 


\section{Introduction}

Understanding crime trends, including factors that drive fluctuations, is fundamental to the study of crime. Because crime trends are dynamic, gaining insight into mechanisms that contribute to variance in crime patterns is an important area of development for crime scholars. Accordingly, an array of factors has been invoked to explain changes in crime trends, including economic-based determinants. Investigations into the crime-economy relationship resulted in the emergence of a huge literature spanning a range of academic disciplines and drawing upon a variety of theories, most of which relate either to the motivational, opportunity or rational choice perspectives (Cook \& Watson, 2014).

Early in the theoretical literature, scholars generally agreed that the unemploymentcrime relationship was positive: an increase in unemployment leads to increases in crime (Cook \& Watson, 2014). However, a review of the empirical research portrays an inconsistency in previous research (Chiricos, 1987; Cook \& Watson, 2014). Limitations in earlier studies may have been attributed to the fact that researchers did not consider theoretically similar mechanisms within a common framework, further contributing to mixed findings. Cantor and Land (1985) recognized the constraints of having disjointed theoretical components and sought to remedy this limitation. In doing so they formulated a model of unemployment and crime that effectively integrated previously fragmented theoretical approaches. The result was a model that synthesized two distinct and counterbalancing structural effects of unemployment on crime: an increase in unemployment has a lagged positive effect on crime through increased motivation and a 
contemporaneous negative effect on crime because of increased guardianship and reduced opportunity. Currently, the bulk of crime-economy literature is either critical of, or premised on, the Cantor and Land (1985) model of unemployment and crime.

Some of this literature has focussed on the use of longitudinal data and its corresponding statistical techniques. Longitudinal data enable the researcher to disentangle the temporal ordering of variables, shedding light on the causal relationships to address questions of variation or change over time (Phillips \& Greenberg, 2007). However, the statistical models within much of the current literature do not allow for the simultaneous identification of the long- and short-run effects stated in the Cantor and Land (1985) model. Additionally, the previous research testing this model has assumed timestable relationships for the unemployment rate.

To address this issue, the current analysis considers the methodological and empirical issues previously mentioned using data from the 10 Canadian provinces between 1981 and 2009. Moving beyond previous inquiries, the Cantor and Land (1985) model of unemployment and crime is extended through the use of the decomposition model with time-varying effects for the unemployment rate on multiple crime types. The aim in adopting a time-varying approach to specifying the Cantor and Land (1985) model is to investigate if the relationship between unemployment and crime is stable over time, and if that (in)stability depends on the crime type under analysis.

\section{Previous research}


Early research on the crime-economy relationship generally occupied one of two theoretical frameworks: motivation or opportunity, both of which were premised on the conceptual framework of routine activity theory (Britt, 1997; Cantor \& Land, 1985;

Chiricos, 1987; Cohen \& Felson, 1979). All this changed when Cantor and Land (1985) formulated a model that would effectively integrate these frameworks. In their model of unemployment and crime, Cantor and Land (1985) posited that by altering the conditions of social strain and social control, economic change (unemployment rate) would positively impact criminal motivation. Also, economic changes influence the availability of vulnerable targets and, hence, increase the number of available criminal targets, opportunities (Phillips \& Land, 2012, p. 682). Criminal motivation was theorized as having a lagged effect, taking time to develop as individuals do not immediately turn to illegitimate activity in the face of economic hardship. Conversely, the opportunity effect occurs immediately because unemployment instantly alters the duration and frequency that individuals are away from the home: being unemployed leads to a shift in routine activities toward the home that allows people to guard person and property making them less susceptible to victimization (Cantor \& Land, 1985). Finally, Cantor and Land (1985) found that both motivation and opportunity matter empirically, particularly for property crime, but operated at different time frames. Motivation matters in the long run, due to the lagged effect, while opportunity matters in the short run, as the effect is immediate.

Since its inception, researchers have argued over the empirical validation of the Cantor and Land (1985) model, more specifically whether opportunity actually dominates motivation. However, the theory behind the model is not often questioned (Andresen, 2013a). Still, two major issues have been raised concerning to the current state of empirical 
inquiry on unemployment and crime: the first pertains to disagreements on the empirical methods, primarily the statistical models used to test the Cantor and Land (1985) model; and second is a set of issues relating to the appropriateness of using unemployment as an isolated measure to test economic performance (Andresen, 2013a; Arvanites \& DeFina, 2006). Proper specification of the Cantor and Land (1985) model will assist in bridging inconsistencies in the results due to discrepancies in method selection. Likewise, because the empirical testing of a model is sensitive to both the variables chosen and the statistical method employed, in order to make conclusive statements on the model being tested and the theoretical relationships it represents, proper specification is crucial (Andresen, 2015).

The issue of whether the opportunity effect dominates the motivation effect has been one of the most contentious within the literature. Hale and Sabbagh (1991) argue that Cantor and Land's (1985) results were likely invalid as the methodological approach adopted by these researchers had fundamental flaws (see Cantor and Land (1991) for a response). Accordingly, Hale and Sabbagh (1991) focused their analysis on determining opportunity and motivation effects using time series data from England and Wales. The results indicated the presence of a motivational effect that was positively associated with crime but did not find evidence for an opportunity effect. Field (1990) demonstrated the importance of incorporating other economic factors when evaluating the unemploymentcrime relationship as concentrating on unemployment alone may lead to model misspecification. For instance, Field (1990) found that for property crime, personal consumption better captures the economic-crime relationships than unemployment; Rosenfeld and Fornango (2007) found similar results in the context of consumer sentiment. Field (1990) concluded that in times when growth in personal consumption is on the 
decline, property offenses will decrease, consistent with the Cantor and Land (1985) model.

Smith et al. (1992) conducted a time series analysis to determine relationships among race and gender specific rates of unemployment and corresponding rates of arrest. Specifically, Smith et al. (1992) sought to determine whether the unemployment-crime relationship differed in directionality and/or intensity when distinguished in terms of age and race from findings for the general population. Overall, initial findings closely resembled those of Cantor and Land (1985), and support was found for both the motivation and opportunity effect. With respect to age and race, an increase in unemployment had a positive motivational effect for property crimes among all groups, including older and majority status groups. In particular, those of Western European descent were more susceptible than African Americans to the motivational impact of fluctuations in the unemployment rate (Smith et al., 1992).

Britt (1997) extended the work of Smith et al. (1992) and re-evaluated the unemployment-crime relationship by testing for variations by age group and considering changes over time. By incorporating age structures into this analysis, Britt (1997) found that homicide, robbery, and burglary had positive relationships with unemployment rates for adults, but unemployment rates for youth were negatively related to homicide and aggravated assault. No support was found for an increasing motivational effect of unemployment over time.

Greenberg (2001) raised concerns on the procedures employed by Cantor and Land (1985), and successive studies that relied on the Cantor and Land approach. According to Greenberg (2001), concerns with the unemployment and crime literature were plentiful, 
ranging from statistical misspecification to the operationalization of independent variables to units of analysis to statistical/econometric methods. Greenberg (2001) went as far to say that "many_perhaps most—sociological analyses of crime rate time series...suffer from serious methodological deficiencies" (Greenberg, 2001, p.323) (see Cantor and Land (2001) for a response). It is important to note that the purpose of the original Cantor and Land (1985) was to provide a functional model of the crime-economy relationship, not provide the "correct" functional form (Cantor \& Land, 1991).

Levitt (2001) expanded on the issues raised by Greenberg (2001) and gave special attention to the flaws of using nationally aggregated data to distinguish between two alternative behavioral explanations for a link between unemployment and crime. Levitt (2001) used a state level panel data set and estimated the data using a fixed effects panel data model that allowed for the measure of short versus long run effects in the unemployment and crime model. Levitt (2001) found a negative or statistically insignificant parameter for the relationship between unemployment and crime, supporting the opportunity effect of the Cantor and Land (1985) model. The results pertained specifically to opportunity effects because fixed effects panel data models specify short-run relationships that correspond to opportunity/contemporaneous effects. Because Cantor and Land (1985) posited the motivational (long-run) and opportunity (short-run) effects to be separate and distinguished structures, in testing the model it is critical to employ a statistical method that is capable of distinguishing the two mechanisms (Levitt, 2001).

Phillips and Land (2012) conducted what is probably the most comprehensive research on the relationship between unemployment and crime to date. In their empirical evaluation, they considered counties, states, and the United States as a whole. Essentially, 
Phillips and Land (2012) incorporated Levitt's (2001) recommendation that disaggregated data should be used when evaluating the relationship between crime and economic change of the state and national levels. Strong support was found for the Cantor and Land (1985) model, with the expected parameter sign estimated in 78 of 84 cases. In addition, Phillips and Land (2012) found that the effects of motivation were stronger for property crimes than violent crimes.

More recent are the empirical contributions of Andresen (2012, 2013a, 2015). Andresen (2012) was the first to use a panel of census tracts to evaluate the Cantor and Land (1985) model, the smallest unit of analysis used to analyze the model thus far. Andresen's (2012) approach was a departure from previous studies, in that his primary interest was not with the effects of motivation versus opportunity, per se, but rather his study centered on long run versus short run effects of economic changes on crime. In his analysis, Andresen (2012) found unemployment to be positively associated with various crime types in the long run and negatively associated with crime in the short run, consistent with the Cantor and Land (1985) model, using the decomposition model.

Andresen (2013a, 2015) continued these efforts and addressed methodological and empirical issues of previous research. Supplementary to the work of Arvanites and DeFina (2006), who emphasized the importance of considering different measures of the economy, Andresen (2013a, 2015) addressed measurement concerns related to the use of a single measure, unemployment, to represent the entire state of the economy and included four economic measures into his analysis (unemployment, GDP, GDP per capita, and low income). The end result was that all four economy related variables mattered for property and violent crime, but the signs and magnitudes of the estimated parameters were 
dependent on context (Andresen, 2013a, 2015). A natural question to ask at this point is whether or not estimated parameters are dependent on time.

\section{Data, methods, and theoretical expectations}

\section{Data}

For our analyses we use a panel data set that contains 10 Canadian provinces, 1981-2009. The Canadian provinces range in population from just under 150,000 persons (the second lowest population count is over 500,000) to just under 13 million persons in 2009; the land areas of the provinces range from 5660 to 1.5 million square kilometers. Though large land areas, approximately 80 percent of the Canadian population lives in urban areas. All data were obtained from Statistics Canada's Canadian Socio-economic Information Management (CANSIM) database. When considering variation or change over time, panel data prove ideal because the data are comprised of two distinct dimensions: a spatial and a temporal unit. The combination of time series and cross-sectional elements enables the researcher to disentangle the temporal ordering of variables and, thus, shed light on the causal relationships among them—something that would be difficult to achieve using only one of these two dimensions (Phillips \& Greenberg, 2007).

The spatial dimension pertains to a set of cross-sectional units: these units could be countries, states, counties, firms, groups of people, or even individuals. In the current analysis our cross-sectional units are taken from the 10 Canadian provinces over a span of 33 years (1981-2009), producing 29 units of observation for each of the 10 provinces, totaling in 290 observations for each variable. The temporal dimension pertains to periodic observations of a set of variables characterizing these cross-sectional units over a 
particular time span. In the current context, panel data analysis is fitting as both the space and time dimensions of the data permit the evaluation of the Cantor and Land (1985) model in an empirical context that considers temporal change. Furthermore, because the data set covers a comprehensive period, stable and unstable markets conditions are represented within the data. More precisely, the nature of the data allows for the extent of variation in both crime and economic conditions to be studied over an extended period, allowing low-frequency or long-term variation in the measures to be identified within the current study (Gould, Weinberg \& Mustard, 2002).

In our analyses we consider both property and violent crime. To account for property crime, shoplifting, theft, burglary, theft of vehicle, and theft from vehicle are selected for analyses. All property crimes, with the exception of shoplifting are expected to demonstrate negative contemporaneous effects (opportunity) and positive lagged effects (motivational) with unemployment. Shoplifting presents a unique opportunity to isolate and test the motivational structure of the Cantor and Land (1985) model. Testing this crime type makes it possible to assess whether structural unemployment does in fact lead to an expected positive relationship with shoplifting, indicating a positive motivational effect and a negative or null contemporaneous opportunity effect. Violent crime considers sexual assault, homicide, assault, and robbery. All crimes are measured as the natural logarithm of the crime rate per 100,000 inhabitants. Taking the natural logarithm of a rate or raw count allows for comparisons to be made in terms of percent change in the crime rate and allows for ease of interpretation, elasticities (Wooldridge, 2010). Descriptive statistics for the crime rates are shown in Table 1. 
The primary independent variables of interest consist of multiple economic measures: unemployment, gross domestic product (GDP), and low income. Unemployment is measured as the percentage of unemployed persons relative to the 15-64-year-old work force in each province ${ }^{1}$; GDP and GDP per capita are measured as the natural logarithm of millions of 2002 constant dollars and GDP per capita, respectively, representing the size of the economy and the average income in the economy. The natural logarithm was taken for the GDP variables in order to provide some form of normalization and account for the variation in economic activity between each province, similar to Arvanites and DeFina (2006). Finally, low income is measured as the natural logarithm of the number of families spending 20 percent or more after-tax income than average on essential needs such as food, clothing, and shelter, as defined by Statistics Canada.

In order to identify any time-varying components of the relationship between the unemployment rate and crime, in addition to the actual unemployment rate, the unemployment rate is interacted with trend variables. Three trend variables are calculated: linear $(1,2,3, \ldots)$, quadratic $(1,4,9, .$.$) , and cubic (1,8,27, \ldots)$ trend variables are calculated and then multiplied by the unemployment rate. This leads to four unemployment rate variables (base, linear trend, quadratic trend, and cubic trend) that when taken together can represent changes in the relationship between the unemployment rate and crime. For example, if only the base unemployment rate is statistically significant, all prior research in this area was safe to assume (implicitly or not) that the relationship between the unemployment rate and crime does not change over time. However, if one or more of the

\footnotetext{
${ }^{1}$ The standard working age range in Canada is 15-64, with retirement often occurring at 65.
} 
unemployment rate trend variables is statistically significant, then this relationship is not constant over time.

We also include a number of control/contextual variables: incidents per officer, correctional expenditures as a percentage of the GDP, number of police officers, and officers per capita. The number of police officers and the incidents per officer are both measured as the natural logarithm of the count of police officers and criminal incidents per sworn officer, respectfully, and are expected to have positive lagged and contemporaneous relationships with crime. Because these variable capture a work-load issue, increases in these measures may not only demonstrate higher criminal incidents in an area but also exhibit a relative underrepresentation of the police or a lack of formal guardianship (Andresen, 2013a, p. 223). Correspondingly, incidents per officer reveal regional differences in crime, as provinces with higher incidents indicate greater instances of crime and vice versa. The interaction between correctional spending as a percentage of GDP and officers per capita may demonstrate a deterrent effect that could lead to differences in crime rates between provinces; for example, increased funding for corrections and greater numbers of officers per capita may create a deterrent effect by decreasing the circulation of motivated offenders and increasing guardianship, but it may simply be indicative of larger offending populations (for a number of social reasons) criminal opportunities/vulnerabilities—see Chalfin and McCrary (2017) fo ra review of this literature.

Additionally, we include alcohol spending as a percentage of GDP, the Gini index and young males to capture the presence of motivated offenders. Young males are measured as the natural logarithm of the count of young males in the population aged 15-29. While the 
Gini index is commonly used to measure inequality, an index of zero would represent perfect equality and as the index increases so does the perceived level of inequality. And alcohol consumption is commonly known for its relationship with (violent) crime (Grubesic \& Pridemore, 2011). Taken together, these variables are expected to have a positive relationship with crime. Because young males are deemed to be the most crime prone sub population (Hirschi \& Gottfredson, 1983; Kennedy \& Forde, 1990; Miethe et al., 1987) and the Gini coefficient represents the relative economic hardship that could increase criminal motivation, jointly these variables could lead to increases in illegitimate economic activity. Finally, because the data are from the years 1981-2009, three trend variables were included in the analyses (Trend, Trend-squared, and Trend-cubed) to account for the sharp increase in all crime rates during the 1980s and the subsequent crime drop in the 1990s (see Farrell et al (2015) for a discussion of the crime drop and its implications for criminological research). Lastly, we include two measures of migration: interprovincial and international migration. Most recent research has shown that these variables are negatively related with crime-see Andresen (2013b). Descriptive statistics and correlations for the independent and control/contextual variables are presented in Tables 1 and 2.

\section{$<$ Insert Tables 1 and 2 About Here>}

\section{Statistical modeling: the decomposition model}

In the analyses below, we employ a technique that allows for the identification of long- and short-run effects to be estimated simultaneously, the decomposition model. The decomposition model is specifically used to test the temporal (in)stability between unemployment and various 
classifications of violent and property crime in Canadian provinces. The unemployment rate is measured as a time-stable variable as well as having linear, quadratic, and cubic trends over time. The decomposition modeling approach can be estimated using the following general specification:

$$
Y_{j t}=\alpha+\sum_{i=1}^{k}\left[\beta_{i} X_{j i}\right]+\sum_{i=1}^{k}\left[\gamma_{i}\left(x_{j i t}-X_{j i}\right)\right]+\varepsilon_{j t}
$$

where $Y_{j t}$ is the natural logarithm of the crime rate per 100,000 residents in province $j$ at time $t, \alpha$ is the common intercept, $\beta_{i}$ is the estimated parameter for the between-effect (long-run effect) for variable $X_{i}$ in province $j\left(X_{j i}\right), X_{j i}$ is the average value for $x_{j i t}, \gamma_{i}$ is the estimated parameter for the within-effect (short-run/fixed effect) for variable $X_{i}$ in province $j\left(X_{j i}\right)$, that is measured as deviations from its average value over the time frame of analysis $\left(x_{j i t}-X_{j i}\right)$, providing the equivalent of fixed effect estimation within the model. These calculations are performed for all independent variables under analysis. All analyses are undertaken using R: A Language and Environment for Statistical Computing $<$ http://www.r-project.org/>.

\section{Results}

The results from the decomposition models are presented in Tables 3 and 4 (long run effects) and Tables 5 and 6 (short run effects)—correctional spending per capita, percent international immigrants, and percent interprovincial migrants are excluded from the long run estimates and officers per capita is excluded from the short run estimates due to multicollinearity issues. The Adjusted $R^{2}$ values range from 0.699 to 0.99 , with most values being greater than 0.95 . These large magnitude values are not uncommon when using 
panel data, particularly with the long time series component of the panel data; rather, the relatively low magnitude value for homicide, 0.699 , is more noteworthy, likely due to the lack of statistical significance for the long-run effects.

Overall, considering the control variables, most of the variables are statistically significant with a lot of consistency for estimated parameter sign and magnitude within violent crime and within property crime. The crime types of homicide, robbery, and shoplifting deviate from their other violent and property crime types, respectfully. However, it should be noted that robbery presents results that are more in line with the property crime results. This is not surprising given the economic-based incentive of robbery being similar to property crimes. In fact, this has led to some scholars referring to robbery as a violent property crime (Indermaur, 1995). There are no obvious explanations for the deviations in the results for homicide and shoplifting aside from homicide being a relatively rare crime type in Canadian provinces that, subsequently, has a lot more volatility than most socio-demographic and socio-economic variables

$<$ Insert Table 3 About Here>

As noted above, all dependent variables are measured as natural logarithms and all of the control variables are measured as natural logarithms or as percentages such that the estimated parameters can be interpreted as elasticities: percentage change in the dependent variable given a 1 percent change in the independent variable(s). With this in mind, it can be seen that the largest effect sizes for long-run relationships are for GDP, young males, and police officers per capita (violent crime), and GDP and young males (property crime); the largest effects sizes for the short-run relationships are GDP and GDP per capita (violent crime), and GDP, GDP per capita, and young males (property crime). 
However, it is important to note that the actual magnitudes for the short-run effects are much smaller than for the long-run effects.

$<$ Insert Table 4 About Here>

Turning to the results of interest, the unemployment rate, the base unemployment rate (the time-stable component) is expected to be positive in the long-run and negative in the short-run, as discussed above. As shown in Tables 3 and 5, the long- and short-run effects for total and violent crime types are as expected (when statistically significant) for all crime types aside from total and robbery. For property crime, Tables 4 and 6 , the longrun effects are only consistent for shoplifting, with burglary and theft of vehicle having statistically significant and negative estimated parameters-this is similar to robbery, when it is considered a violent property crime. The short-run effects are only statistically significant for shoplifting (positive, counter to expectations) and theft of vehicle (negative, consistent with expectations). As such, overall it would appear as though violent crime in Canadian provinces is most consistent with the Cantor and Land (1985) model, with property crime having mixed results.

$<$ Insert Table 5 About Here $>$

Turning to the time-varying estimated parameters for the unemployment rate, these variables are all statistically insignificant for total and violent crime with the exception of assault. For property crime, theft, burglary, theft of vehicle, and theft from vehicle have statistical significance for the long-run effects, whereas aggregate property crime, shoplifting, and theft from vehicle have statistical significance for the short-run effects. These results are discussed further below, but at this stage there is evidence for the 
presence of time-varying estimated parameters, particularly for property crime types, when looking for support of the Cantor and Land (1985) model.

$<$ Insert Table 6 About Here>

\section{Discussion}

The summary of the results for the unemployment rate parameter estimates are presented in Table 7. The first two columns of Table 7 include the sign of the estimates for the longrun and short-run effects of unemployment on crime without the linear, quadratic, and cubic variables included - this is how the unemployment rate has been modeled in previous research. As can be seen, aside from total crime, the long-run estimates for the effect of changes in the unemployment rate on crime are the same sign when both are statistically significant; generally speaking, there is a lot of consistency across the results. However, the results are only consistent with the Cantor and Land (1985) model for violent crime types, aside from robbery. For the short-run effects, there is far less consistency. Without the time-varying unemployment rate variables, the short-run effect is statistically significant in 7 of the 12 cases and negative (supporting the hypothesis within the Cantor and Land (1985) model) in 4 of those 7 cases. In other words, without the time-varying unemployment rate variables, there is more support for the Cantor and Land (1985) model than not, especially in the case of violent crime types.

$<$ Insert Table 7 About Here>

When the time-varying unemployment rate variables are included, however, notable changes occur. For violent crime types, as noted above, only the violent crime type 
of assault has statistically significant time-varying parameter estimates. This bodes well for previous research that has investigated the effect of unemployment on violent crime types, only considering time-stable unemployment rate parameters. The result for assault that is curious, however, is that the expected negative short-run relationship may only be present for particular time periods within our overall study period. In order to illustrate the impact of the time-varying parameters, each of the parameters for the unemployment rate variables (base, linear, quadratic, and cubic) are multiplied by their respective trend values and plotted in Figure 1.

Specifically, as shown in Figure 1, the short-run effect of the unemployment rate on crime is negative during the 1980s and the late-2000s; for the 1990s and the early-2000s the short-run effect is positive, opposite of expectations. What this means is that if a research study only analyzed the 1990s, there would not be statistical support for the Cantor and Land (1985) model in the short-run. Considering the entire 29-year study period, as shown in Table 7, the short-run effect for the unemployment rate on assault is negative, in support of the Cantor and Land (1985) model. This means that those early and latter year under analysis are dominating the time-stable results. As such, if the effect of unemployment on crime waxes and wanes, basing public policy on this model will only have support at particular times.

For (violent) property crime types, there are no changes in sign for long-run relationships when estimated parameters are statistically significant. However, the longrun relationship between the unemployment and crime is always negative, counter to the expectations of the Cantor and Land (1985) model, except for shoplifting when the timevarying unemployment rate variables are included in the analysis. The long-run 
relationships are only time-varying for theft, burglary, theft of vehicle, and theft from vehicle. Moreover, aside from theft from vehicle, the long-run relationship is always negative, regardless of the time period considered. And for theft from vehicle, the long-run relationship only becomes positive at the very end of the study period; as such, this could just be an artefact of the functional form at the tail-end of the time series.

$<$ Insert Figure 1 About Here $>$

When considering the short-run relationships for (violent) property crime types, aggregate property crime, shoplifting, and theft from vehicle have statistically significant time-varying relationships between the unemployment rate and crime. In all three cases, the relationship is positive, negative, and zero, depending on the time period within the study period here. Aside from aggregate property crime the overall short-run relationship is positive, counter to the expectations of the Cantor and Land (1985) model. Consequently, only if one is analyzing aggregate property crime would support for the Cantor and Land (1985) model be found for the short-run.

A natural question to ask at this point is: why is this the case? Perhaps there were different patterns in the unemployment rate during these different time periods that can explain these changes in the relationship over time, particularly in the short-run? The unemployment rate for Canada, 1981 - 2009, is shown in Figure 2 with vertical lines at 1990 and 2000, for reference. It can be seen in this Figure that the same general pattern is present in the 1980s and the 1990s: an increase in the unemployment rate for the first few years of the decade, followed by a decrease until the end of the decade. With no regularity in the time-varying parameters for the unemployment rate, or any regularity across crime types, this does not bode well for an explanation to the time-varying relationship for the 
unemployment rate in the short-run. And with the significantly different temporal pattern of the unemployment rate in the 2000 s, modestly increasing then decreasing then increasing again (with none of those changes close in magnitude to those in the 1980s and 1990s), no explanation is found here either.

$<$ Insert Figure 2 About Here>

It is important to note here that this is far from a death knell for the Cantor and Land (1985) model of unemployment and crime. The results for violent crime are generally consistent with expectations and time stable, and not all of the property crime relationships are found to be counter to expectations. The finding that long- and short-run relationships for property crime and the unemployment rate are time-varying is important for policy formation: sometimes it works, sometimes it does not, and sometimes it works in the opposite way expected. As such, until a better understanding is obtained regarding this relationship any formation of policy along these lines should be done with caution.

From a theoretical perspective, this finding is somewhat perplexing. For some crime types (burglary, theft, theft of vehicle, and theft from vehicle) the long-run relationship with the unemployment rate is negative. This is counter to social disorganization theory that is considered to be a more long-run theory of crime, but is not counter to expectations for routine activity theory. Though routine activity theory is used as a short-run explanation for the relationship between unemployment and crime in the Cantor and Land (1985) model, it must be remembered that Cohen and Felson's (1979) original formulation of routine activity theory was used to explain long-run changes in the crime rate at the national level. Given the general consistency within violent crime and within (violent) property crime, there is no reason why different mechanisms cannot be in place for two 
difference crime classifications that have different motivational factors using the same theory: the long-run impact of unemployment may impact the motivational aspect (increase the number of motivated offenders) of violent crime because of the increased economic strain, but decrease the number of suitable targets available because people have less disposable income and increasingly spend more time at home protecting person and property. However, such explorations run the risk of making routine activity theory unfalsifiable and, therefore, need to be done with caution.

Regardless, more research needs to be undertaken to investigate the generalizability of this finding. The presence of time-varying relationships, overall, is arguably more important for the Cantor and Land (1985) model than explaining the signs of estimated parameters that are counter to expectations, because the hallmark of this model is the presence of short- and long-run effects-different signs for these estimated parameters may simply be due to the Canadian context. Though units of analysis the size of Canadian provinces are not inconsistent with testing of the Cantor and Land (1985) model, other research in different contexts is necessary to test the presence of time-varying relationships. These different contexts should include areas as large as U.S. states, but also counties, cities, and neighborhoods. As discussed above, the importance of multiple measures of the economy and disaggregated crime types should prove to be instructive when investigating the (in)stability of the relationship between unemployment and crime. 


\section{References}

Andresen, M. A. (2012). Unemployment and crime: A neighborhood level panel data approach. Social Science Research, 41(6), 1615-1628.

Andresen, M. A. (2013a). Unemployment, business cycles, crime, and the Canadian provinces. Journal of Criminal Justice, 41(4), 220-227.

Andresen, M. A. (2013b). International immigration, internal migration, and homicide in Canadian provinces. International Journal of Offender Therapy and Comparative Criminology, 57(5), $632-657$.

Andresen, M.A. (2015). Unemployment, GDP, and crime: the importance of multiple measurements of the economy. Canadian Journal of Criminology and Criminal Justice, 57(1), 35 - 58.

Arvanites, T. M., \& Defina, R. H. (2006). Business cycles and street crime. Criminology, $44(1), 139-164$.

Britt, C. L. (1997). Reconsidering the unemployment and crime relationship: Variation by age group and historical period. Journal of Quantitative Criminology, 13(4), 405428.

Cantor, D., \& Land, K. C. (1985). Unemployment and crime rates in the post-world war II united states: A theoretical and empirical analysis. American Sociological Review, $50(3), 317-332$.

Cantor, D., \& Land, K. C. (1991). Exploring possible temporal relationships of unemployment and crime: A comment on Hale and Sabbagh. Journal of Research in Crime and Delinquency, 28(4), 418-425 
Cantor, D., \& Land, K. C. (2001). Unemployment and crime rate fluctuations: A comment on Greenberg. Journal of Quantitative Criminology, 17(4), 329-342.

Chaflin, A., \& McCrary, J. (2017). Criminal deterrence: A review of the literature. Journal of Economic Literature, 55(1), 5 - 48.

Chiricos, T. G. (1987). Rates of crime and unemployment: An analysis of aggregate research evidence. Social Problems, 34(2), 187-212.

Cohen, L. E., \& Felson, M. (1979). Social change and crime rate trends: A routine activity approach. American Sociological Review, 44(4), 588-608.

Cook, S., \& Watson, D. (2014). A re-examination of the opportunity and motivation effects underlying criminal activity. Criminology and Criminal Justice, 14(4), 458-469.

Farrell, G., Tilley, N., Tseloni, A., \& Mailley, J. (2010). Explaining and sustaining the crime drop: Clarifying the role of opportunity-related theories. Crime Prevention \& Community Safety, 12(1), 24-41.

Field, S. (1990). Trends in crime and their interpretation: A study of recorded crime in post war England and Wales. London: Home Office.

Gordon, R. A. (1968). Issues in multiple regression. American Journal of Sociology, 73(5), $592-616$.

Gould, E. D., Weinberg, B. A., \& Mustard, D. B. (2002). Crime rates and local labor market opportunities in the United States: 1979-1997. Review of Economics and Statistics, 84(1), 45-61.

Greenberg, D. F. (2001). Time series analysis of crime rates. Journal of Quantitative Criminology, 17(4), 291-327.

Grubesic, T. H. and Pridemore, W. A. (2011). Alcohol outlets and clusters of violence. 
International Journal of Health Geographics, 10(1), Article 30.

Hale, C., \& Sabbagh, D. (1991). Testing the relationship between unemployment and crime: A methodological comment and empirical analysis using time series data from England and Wales. Journal of Research in Crime and Delinquency, 28(4), 400-417.

Hirschi, T., \& Gottfredson, M. (1983). Age and the explanation of crime. American Journal of Sociology, 89(3), 552-584.

Indermaur, D. (1995). Violent property crime. Sydney: Federation Press.

Kennedy, L. W., \& Forde, D. R. (1990). Routine activities and crime: An analysis of victimization in Canada. Criminology, 28(1), 137-152.

Land, K. C., McCall, P. L., \& Cohen, L. E. (1990). Structural covariates of homicide rates: are there any invariances across time and social space? American Journal of Sociology, 95(4), 922-963.

Land, K. C. (2015). Solving criminological puzzles. In Maltz, Michael D., Rice, Stephen K. (Eds.), Envisioning criminology: Researchers on research as a process of discovery (pp. 173-181). New York, NY: Springer.

Levitt, S. D. (2001). Alternative strategies for identifying the link between unemployment and crime. Journal of Quantitative Criminology, 17(4), 377-390.

McCall, P. L., Land, K. C., \& Parker, K. F. (2010). An empirical assessment of what we know about structural covariates of homicide rates: A return to a classic 20 years later. Homicide Studies, 14(3), 219-243.

McCall, P. L., Land, K. C., \& Parker, K. F. (2011). Heterogeneity in the rise and decline of citylevel homicide rates, 1976-2005: A latent trajectory analysis. Social Science Research, 40(1), 363-378. 
Miethe, T. D., Stafford, M. C., \& Long, J. S. (1987). Social differentiation in criminal victimization: A test of routine activities/lifestyle theories. American Sociological Review, 52(2), 184-194.

Phillips, J. A., \& Greenberg, D. F. (2008). A comparison of methods for analyzing criminological panel data. Journal of Quantitative Criminology, 24(1), 51-72.

Phillips, J., \& Land, K. C. (2012). The link between unemployment and crime rate fluctuations: An analysis at the county, state, and national levels. Social Science Research, 41(3), 681-694.

Rosenfeld, R., \& Fornango, R. (2007). The impact of economic conditions on robbery and property crime: The role of consumer sentiment. Criminology, 45(4), 735-769.

Smith, M. D., Devine, J. A., \& Sheley, J. F. (1992). Crime and unemployment: Effects across age and race categories. Sociological Perspectives, 35(4), 551-572.

Wooldridge, J. M. (2010). Econometric analysis of cross section and panel data (2 $2^{\text {nd }}$ ed.). Cambridge, MA: MIT press. 
Figure 1. Time-varying effects, $1981-2009$

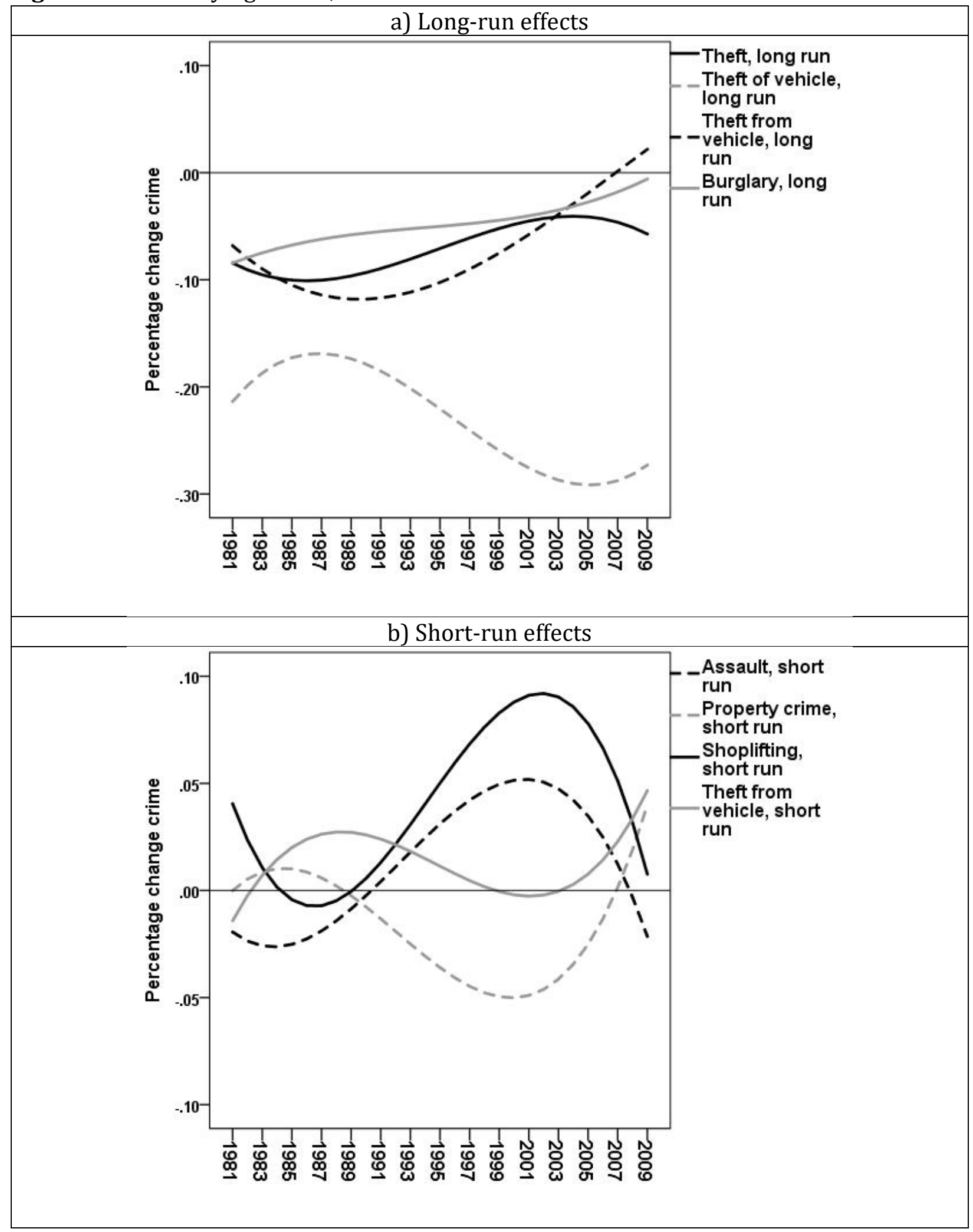


Figure 2. Unemployment rate, Canada, $1981-2009$

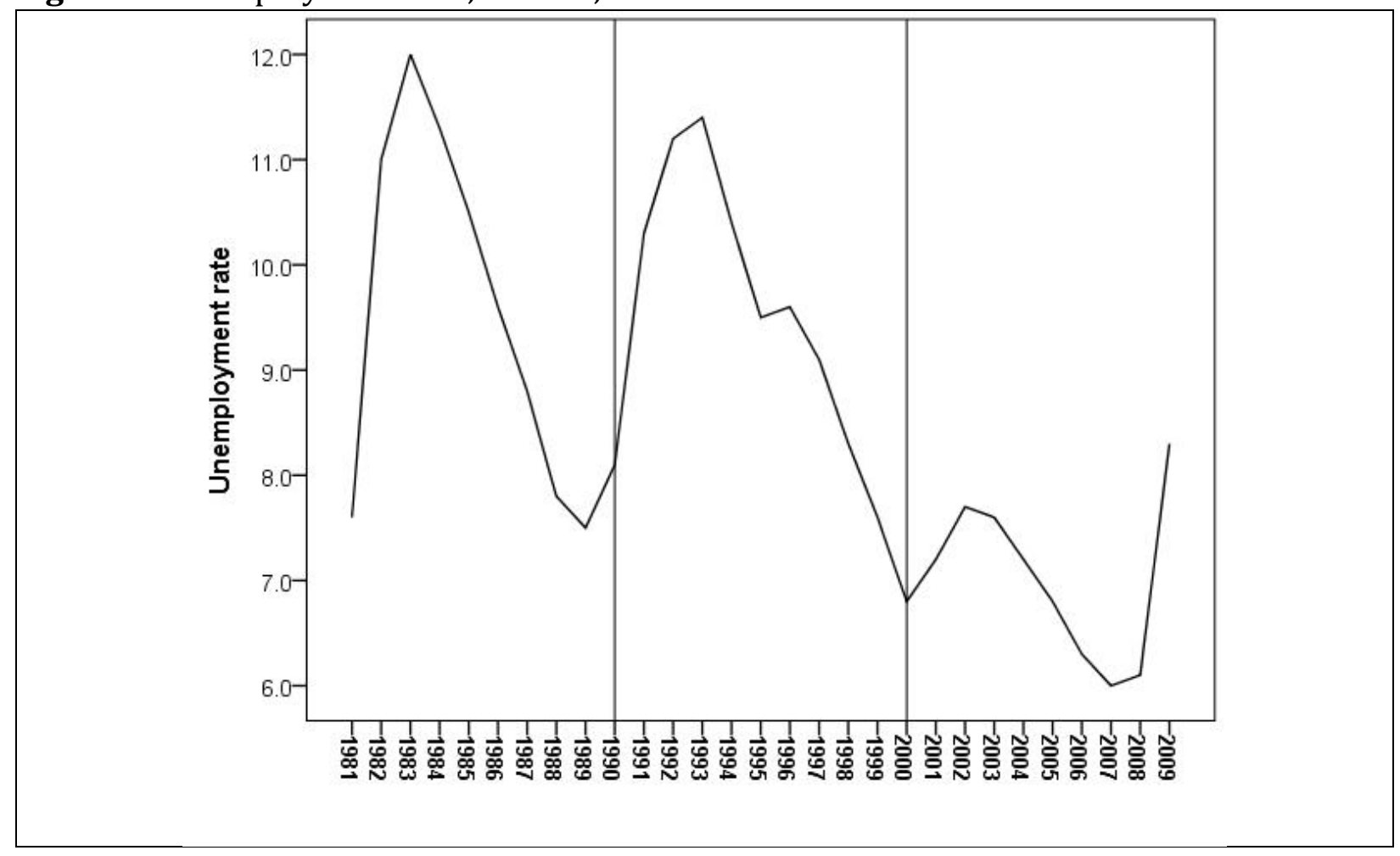


Table 1. Descriptive statistics, dependent and independent variables, 1981 - 2009

\begin{tabular}{|l|r|r|r|r|}
\hline & Minimum & Maximum & Mean & Std. Deviation \\
\hline Total crime & 4711.3 & 15417.3 & 8652.5 & 2567.9 \\
\hline Violent crime & 373.1 & 3154.0 & 1218.6 & 538.4 \\
\hline Sexual assault & 26.2 & 227.4 & 95.2 & 39.9 \\
\hline Homicide & 0.0 & 5.1 & 2.0 & 1.1 \\
\hline Assault & 193.4 & 1677.0 & 744.9 & 284.6 \\
\hline Robbery & 4.9 & 209.1 & 78.1 & 53.1 \\
\hline Property crime & 2427.4 & 9152.8 & 5265.6 & 1694.7 \\
\hline Shoplifting & 62.0 & 650.6 & 332.9 & 128.3 \\
\hline Theft & 592.1 & 5584.0 & 2217.3 & 1240.8 \\
\hline Burglary & 433.6 & 1835.8 & 1005.5 & 362.3 \\
\hline Theft of vehicle & 82.9 & 1366.1 & 401.1 & 255.5 \\
\hline Theft from vehicle & 241.1 & 2827.3 & 966.9 & 538.5 \\
\hline Unemployment rate & 3.4 & 20.2 & 9.969 & 3.7902 \\
\hline GDP, millions & 1994.81 & 527027.08 & 98541.96 & 123131.63 \\
\hline Low income, \% & 4.96 & 20.03 & 11.52 & 2.91 \\
\hline GDP per capita & 16140.80 & 66100.11 & 30562.99 & 8696.57 \\
\hline Young males, \% & 18.13 & 32.60 & 22.94 & 3.12 \\
\hline Gini coefficient & 34.70 & 44.00 & 39.73 & 1.97 \\
\hline Alcohol spending, \% GDP & 0.71 & 3.18 & 1.59 & 0.47 \\
\hline Police officers & 178 & 25,558 & 5519 & 6671 \\
\hline Police officers per capita & 136.76 & 273.63 & 179.11 & 21.00 \\
\hline Incidents per police officer & 24.10 & 84.01 & 48.41 & 13.37 \\
\hline Corrections spending, \% GDP & 0.05 & 0.24 & 0.14 & 0.04 \\
\hline International immigrants, \% & 0.05 & 1.39 & 0.43 & 0.34 \\
\hline Interprovincial immigrants, \% & 0.26 & 4.37 & 1.50 & 0.65 \\
\hline
\end{tabular}


Table 2. Nonparametric correlations, independent variables

\begin{tabular}{|c|c|c|c|c|c|c|c|c|c|c|c|}
\hline & $\mathrm{X}_{2}$ & $\mathrm{X}_{3}$ & $\mathrm{X}_{4}$ & $\mathrm{X}_{5}$ & $\mathrm{X}_{6}$ & $\mathrm{X}_{7}$ & $\mathrm{X}_{8}$ & $X_{9}$ & $\mathrm{X}_{10}$ & $\mathrm{X}_{11}$ & $\mathrm{X}_{12}$ \\
\hline Unemployment rate, $\mathrm{X}_{1}$ & $-.615^{* *}$ & $.191^{* *}$ & $-.733^{* *}$ & $.231^{* *}$ & $-.532^{* *}$ & $.767^{* *}$ & $-.481^{* *}$ & $-.370^{* *}$ & $.116^{*}$ & $-.625^{* *}$ & $.117^{*}$ \\
\hline GDP, millions, $\mathrm{X}_{2}$ & & $.167^{* *}$ & $.719^{* *}$ & $-.153^{* *}$ & $.586^{* *}$ & $-.653^{* *}$ & $.611^{* *}$ & 0.032 & $-.461^{* *}$ & $.808^{* *}$ & $-.510^{* *}$ \\
\hline Low income, $\%, X_{3}$ & & & $-.258^{* *}$ & $.276^{* *}$ & 0.032 & $.157^{* *}$ & $.184^{* *}$ & 0.038 & -0.013 & 0.042 & $-.299^{* *}$ \\
\hline GDP per capita, $\mathrm{X}_{4}$ & & & & $-.418^{* *}$ & $.704^{* *}$ & $-.837^{* *}$ & $299^{* *}$ & $.235^{* *}$ & $-.405^{* *}$ & $.664^{* *}$ & $-.130^{*}$ \\
\hline Young males, $\%, \mathrm{X}_{5}$ & & & & & $-.627^{* *}$ & $.377^{* *}$ & 0.041 & 0.058 & $.281^{* *}$ & $-.199^{* *}$ & $.275^{* *}$ \\
\hline Gini coefficient, $\mathrm{X}_{6}$ & & & & & & $-.647^{* *}$ & $.227^{* *}$ & 0.110 & $-.369^{* *}$ & $.460^{* *}$ & $-.305^{* *}$ \\
\hline Alcohol spending, $\%$ GDP, $\mathrm{X}_{7}$ & & & & & & & $-.367^{* *}$ & $-.236^{* *}$ & $.321^{* *}$ & $-.539^{* *}$ & $.208^{* *}$ \\
\hline Police officers per capita, $\mathrm{X}_{8}$ & & & & & & & & -0.051 & -0.051 & $.465^{* *}$ & $-.541^{* *}$ \\
\hline Incidents per police officer, $\mathrm{X}_{9}$ & & & & & & & & & $.266^{* *}$ & $.260^{* *}$ & $.406^{* *}$ \\
\hline Corrections spending, \% GDP, $\mathrm{X}_{10}$ & & & & & & & & & & $-.229^{* *}$ & $.126^{*}$ \\
\hline International immigrants, $\%, \mathrm{X}_{11}$ & & & & & & & & & & & $-.274^{* *}$ \\
\hline
\end{tabular}

Notes. $^{* *} 5 \%$ significance, ${ }^{* *} 1 \%$ significance. 
Table 3. Decomposition model, long run results, total and violent crime

\begin{tabular}{|l|c|c|c|c|c|c|}
\hline & Total & Violent & Sexual assault & Homicide & Assault & Robbery \\
\hline Unemployment rate, base & $-0.00^{* * *}$ & $0.096^{* * *}$ & $0.242^{* * *}$ & -0.125 & $0.172^{* * *}$ & $-0.770^{* * *}$ \\
\hline Unemployment rate, linear & -0.00 & -0.003 & 0.003 & 0.003 & -0.003 & 0.001 \\
\hline Unemployment rate, quadratic & 0.00 & 0.00 & -0.00 & 0.00 & 0.00 & -0.001 \\
\hline Unemployment rate, cubic & -0.00 & -0.00 & 0.00 & -0.00 & 0.00 & 0.00 \\
\hline Gross domestic product (GDP) & $-1.00^{* * *}$ & $-7.278^{* * *}$ & $-6.484^{* *}$ & 4.158 & $-7.191^{* * *}$ & $-7.687^{* *}$ \\
\hline Low income & $0.00^{* * *}$ & $-1.381^{* * *}$ & $-2.659^{* * *}$ & $1.828^{* * *}$ & $-2.370^{* * *}$ & $6.020^{* * *}$ \\
\hline GDP per capita & $1.00^{* * *}$ & $4.159^{* *}$ & 2.433 & -1.819 & 2.718 & $9.386^{* * *}$ \\
\hline Young males & $-0.00^{* * *}$ & $12.638^{* * *}$ & $21.175^{* * *}$ & $-8.933^{* * *}$ & $19.285^{* * *}$ & $-24.459^{* * *}$ \\
\hline Gini coefficient & -0.00 & $-0.086^{*}$ & $-0.356^{* * *}$ & -0.078 & $-0.186^{* * *}$ & $0.597^{* * *}$ \\
\hline Alcohol spending per capita & $0.00^{* * *}$ & $-0.782^{* *}$ & $-3.204^{* * *}$ & 0.249 & $-1.541^{* * *}$ & $8.959^{* * *}$ \\
\hline Police officers & $1.00^{* * *}$ & -2.677 & $-7.746^{* * *}$ & 2.344 & $-7.314^{* * *}$ & $15.657^{* * *}$ \\
\hline Officers per capita & 0.00 & $5.843^{* * *}$ & $13.17^{* * *}$ & -2.915 & $11.996^{* * *}$ & $-24.084^{* * *}$ \\
\hline Incidents per officer & $1.00^{* * *}$ & $2.599^{* * *}$ & $4.783^{* * *}$ & -0.373 & $3.953^{* * *}$ & $-6.513^{* * *}$ \\
\hline & & & & & 0.699 & 0.962 \\
\hline Adjusted- $R^{2}$ & 0.99 & 0.954 & 0.864 & 0.958 \\
\hline
\end{tabular}

Notes. ${ }^{*} 10 \%$ statistical significance, ${ }^{* *} 5 \%$ statistical significance, ${ }^{* * *} 1 \%$ statistical significance; all inference based on robust standard errors. 
Table 4. Decomposition model, long run results, property crime

\begin{tabular}{|c|c|c|c|c|c|c|}
\hline & Property & Shoplifting & Theft & Burglary & Theft of vehicle & Theft from vehicle \\
\hline Unemployment rate, base & -0.035 & $0.463^{*}$ & -0.077 & $-0.090^{* * *}$ & $-0.232^{* * *}$ & -0.055 \\
\hline Unemployment rate, linear & -0.001 & 0.003 & $-0.009 * *$ & $0.006^{*}$ & $0.021^{* * *}$ & $-0.014^{* * *}$ \\
\hline Unemployment rate, quadratic & 0.00 & -0.001 & $0.001^{* * *}$ & -0.00 & $-0.002^{* * *}$ & $0.001^{* * *}$ \\
\hline Unemployment rate, cubic & -0.00 & 0.00 & $-0.00^{* * *}$ & 0.00 & $0.00^{* * *}$ & -0.00 \\
\hline Gross domestic product (GDP) & 2.057 & $18.535^{*}$ & -3.336 & $3.977^{* *}$ & $8.59 * * *$ & $7.826^{* * *}$ \\
\hline Low income & $0.708^{* * *}$ & -0.941 & 0.00 & $2.294^{* * *}$ & $4.142^{* * *}$ & $1.142^{* * *}$ \\
\hline GDP per capita & -0.399 & $-13.957 *$ & 2.591 & 0.253 & -2.475 & $-4.629 * *$ \\
\hline Young males & $-5.979 * * *$ & -1.621 & -0.257 & $-15.627^{* * *}$ & $-24.497^{* * *}$ & $-13.903^{* * *}$ \\
\hline Gini coefficient & -0.012 & -0.605 & 0.073 & $0.118^{* *}$ & -0.084 & $-0.127^{* *}$ \\
\hline Alcohol spending per capita & $0.739 * * *$ & $-6.056^{* *}$ & 0.481 & $1.119^{* * *}$ & $1.653^{* * *}$ & $2.086^{* * *}$ \\
\hline Police officers & $2.242^{* * *}$ & $-9.222^{*}$ & 3.148 & $7.496^{* * *}$ & $9.229 * * *$ & 2.576 \\
\hline Officers per capita & -1.532 & $14.344^{*}$ & -3.744 & $-7.589 * * *$ & $-12.419^{* * *}$ & -3.158 \\
\hline Incidents per officer & 0.219 & $4.542^{* * *}$ & 0.599 & $-1.424^{* * *}$ & $-2.427^{* * *}$ & 0.155 \\
\hline Adjusted- $R^{2}$ & 0.976 & 0.825 & 0.936 & 0.959 & 0.956 & 0.957 \\
\hline
\end{tabular}

Notes. ${ }^{*} 10 \%$ statistical significance, ${ }^{* *} 5 \%$ statistical significance, ${ }^{* * *} 1 \%$ statistical significance; all inference based on robust standard errors. 
Table 5. Decomposition model, short run results, total and violent crime

\begin{tabular}{|c|c|c|c|c|c|c|}
\hline & Total & Violent & Sexual assault & Homicide & Assault & Robbery \\
\hline Unemployment rate, base & 0.00 & -0.010 & $-0.081^{* *}$ & 0.002 & -0.013 & 0.019 \\
\hline Unemployment rate, linear & 0.00 & 0.003 & 0.014 & 0.008 & $-0.008^{* *}$ & -0.002 \\
\hline Unemployment rate, quadratic & -0.00 & -0.001 & 0.00 & -0.001 & $0.001^{* * *}$ & -0.00 \\
\hline Unemployment rate, cubic & 0.00 & 0.00 & -0.00 & 0.00 & $-0.00 * * *$ & 0.00 \\
\hline Gross domestic product (GDP) & $-1.00^{* * *}$ & $-3.892^{* * *}$ & $-4.467 * * *$ & 0.219 & $-2.596^{* * *}$ & -0.003 \\
\hline Low income & -0.00 & $-0.231^{* * *}$ & $-0.225^{*}$ & 0.059 & -0.116 & $-0.194^{*}$ \\
\hline GDP per capita & $1.00^{* * *}$ & $3.565^{* * *}$ & $3.938^{* * *}$ & 0.373 & $2.503^{* * *}$ & 0.622 \\
\hline Young males & 0.00 & $1.159 * * *$ & $1.672^{* *}$ & -0.208 & 0.183 & -0.702 \\
\hline Gini coefficient & 0.00 & $0.013^{* *}$ & $-0.032^{* * *}$ & $0.049^{*}$ & -0.009 & $0.071^{* * *}$ \\
\hline Alcohol spending per capita & -0.00 & $0.509 * * *$ & 0.362 & $-1.278^{* * *}$ & $0.606^{* * *}$ & $-0.897^{* * *}$ \\
\hline Police officers & $1.00^{* * *}$ & $1.596^{* * *}$ & $0.888^{* *}$ & 0.692 & $1.029 * * *$ & 0.721 \\
\hline Incidents per officer & 1.00 & $0.545^{* * *}$ & 0.005 & $0.624^{* * *}$ & $0.606^{* * *}$ & $0.887^{* * *}$ \\
\hline Correctional spending per capita & $-0.00^{* * *}$ & 0.015 & 0.132 & -0.011 & 0.066 & -0.059 \\
\hline Immigrants, $\%$ & 0.00 & -0.064 & -0.145 & $0.176^{*}$ & -0.005 & 0.046 \\
\hline Interprovincial immigrants, \% & 0.00 & -0.037 & $0.145^{* *}$ & $-0.145^{*}$ & 0.038 & $-0.202^{* * *}$ \\
\hline Adjusted- $R^{2}$ & 0.99 & 0.954 & 0.864 & 0.699 & 0.962 & 0.958 \\
\hline
\end{tabular}

Notes. ${ }^{*} 10 \%$ statistical significance, ${ }^{* *} 5 \%$ statistical significance, ${ }^{* * *} 1 \%$ statistical significance; all inference based on robust standard errors. 
Table 6. Decomposition model, short run results, property crime

\begin{tabular}{|c|c|c|c|c|c|c|}
\hline & Property & Shoplifting & Theft & Burglary & Theft of vehicle & Theft from vehicle \\
\hline Unemployment rate, base & -0.008 & $0.062^{* *}$ & 0.015 & -0.014 & $-0.053^{* *}$ & -0.028 \\
\hline Unemployment rate, linear & $0.009 * * *$ & $-0.024^{* *}$ & -0.003 & 0.006 & 0.013 & $0.015^{* *}$ \\
\hline Unemployment rate, quadratic & $-0.001^{* * *}$ & $0.002^{* * *}$ & 0.001 & -0.001 & -0.001 & $-0.001^{* *}$ \\
\hline Unemployment rate, cubic & $0.00 * * *$ & $-0.00 * * *$ & -0.00 & 0.00 & 0.00 & $0.00^{* *}$ \\
\hline Gross domestic product (GDP) & $-0.551^{* *}$ & $-2.460^{* * *}$ & $-1.366^{* *}$ & $-0.785^{* *}$ & $3.244^{* * *}$ & 0.242 \\
\hline Low income & -0.020 & $0.278^{* *}$ & $0.187^{* *}$ & 0.065 & -0.003 & 0.127 \\
\hline GDP per capita & $0.557^{* *}$ & $1.928^{* * *}$ & $0.959 *$ & $0.667^{*}$ & $-3.059 * * *$ & -0.556 \\
\hline Young males & -0.159 & $2.773^{* * *}$ & -0.147 & 0.214 & $-2.810^{* * *}$ & 0.869 \\
\hline Gini coefficient & 0.004 & $-0.052 * *$ & $-0.029 * * *$ & $0.014^{* *}$ & $0.039 * * *$ & -0.013 \\
\hline Alcohol spending per capita & -0.023 & 0.281 & 0.205 & $-0.218^{* *}$ & -0.157 & -0.055 \\
\hline Police officers & $0.943^{* * *}$ & 0.363 & $1.404^{* * *}$ & 0.293 & -0.022 & $0.674^{* * *}$ \\
\hline Incidents per officer & $1.001^{* * *}$ & $0.513^{* * *}$ & $0.892^{* * *}$ & $1.011^{* * *}$ & $1.279^{* * *}$ & $1.159 * * *$ \\
\hline Correctional spending per capita & -0.004 & -0.201 & $-0.273^{* * *}$ & -0.087 & $0.511^{* * *}$ & $0.172^{* *}$ \\
\hline Immigrants, $\%$ & $0.069 * *$ & 0.073 & $0.269 * * *$ & 0.026 & 0.084 & 0.059 \\
\hline Interprovincial immigrants, \% & $-0.050 * *$ & $0.113^{* *}$ & $0.124^{* * *}$ & $-0.055^{* *}$ & $-0.101^{* * *}$ & $0.094^{* *}$ \\
\hline Adjusted- $R^{2}$ & 0.976 & 0.825 & 0.936 & 0.959 & 0.956 & 0.957 \\
\hline
\end{tabular}

Notes. ${ }^{*} 10 \%$ statistical significance, ${ }^{* *} 5 \%$ statistical significance, ${ }^{* * *} 1 \%$ statistical significance; all inference based on robust standard errors. 
Table 7. Results summary, time-varying effects: total, violent, and property crime

\begin{tabular}{|c|c|c|c|c|c|c|c|c|c|c|}
\hline & & & Long- & n time- & arying & & Short & time-v & ing & \\
\hline & Long-run & Short-run & Base & Linear & Quadratic & Cubic & Base & Linear & Quadratic & Cubic \\
\hline Total crime & + & & - & & & & & & & \\
\hline Violent crime & + & - & + & & & & & & & \\
\hline Sexual assault & + & + & + & & & & - & & & \\
\hline Homicide & - & & & & & & & & & \\
\hline Assault & + & - & + & & & & & - & + & - \\
\hline Robbery & - & & - & & & & & & & \\
\hline Property crime & - & - & & & & & & + & - & + \\
\hline Shoplifting & & + & + & & & & + & - & + & - \\
\hline Theft & & + & & - & + & - & & & & \\
\hline Burglary & - & & - & + & & & & & & + \\
\hline TOV & - & - & - & + & - & + & - & & & \\
\hline TFV & - & & & - & + & & & + & - & + \\
\hline
\end{tabular}

Note. Statistically insignificant results not shown. 